\title{
LAZER E EDUCAÇÃO NO PROGRAMA ESCOLA INTEGRADA
}

\author{
Marcília de Sousa Silva \\ Universidade Federal de Minas Gerais (UFMG), Belo Horizonte - MG, Brasil \\ Hélder Ferreira Isayama** \\ Universidade Federal de Minas Gerais (UFMG), Belo Horizonte - MG, Brasil
}

RESUMO: Propôs-se um estudo de caso sobre as interfaces entre lazer e educação no Programa Escola Integrada, do município de Belo Horizonte, cuja proposta objetiva uma formação diferenciada. A pesquisa utilizou a abordagem do ciclo de políticas (policy cycle approach) para entender os contextos do programa, no qual se interpretaram as concepções de lazer e educação apropriadas pelos sujeitos envolvidos no planejamento e na execução das ações. Conclui-se que as concepções de educação e lazer apropriadas no contexto da prática do programa podem ser interpretadas como funcionalistas, porém, sem serem consideradas negativas. Entretanto, entende-se que não são suficientes para o desenvolvimento de uma cultura política, assentada na formação cultural. As ações educativas planejadas e executadas pelos sujeitos investigados precisam ser redimensionadas e refletidas como promotoras, produtoras e produzidas da e na cultura, além das possibilidades de divertir e alegrar.

Palavras-chave: Concepções. Lazer. Educação. Programa Escola Integrada.

\section{LEISURE AND EDUCATION IN THE INTEGRATED SCHOOL PROGRAM}

ABSTRACT: We proposed a case study of the interfaces between leisure and education in the Integrated School Program, in the city of Belo Horizonte, whose goal proposed a differentiated formation. The research used the approach of the policy cycle (policy cycle approach) to understand the program contexts in which they interpret the concepts of leisure and proper education for those involved in planning and execution. This article concludes the conception of appropriate education and leisure in the context of the practice of the Program can be interpreted as functionalist,

"Doutoranda em Estudos do Lazer pela Universidade Federal de Minas Gerais (UFMG). Professora da Secretaria Municipal de Educação da Prefeitura Municipal de Belo Horizonte. E-mail: < marciliasousasilva@ yahoo.com.br $>$.

“Doutor em Educação Física pela Universidade Estadual de Campinas (UNICAMP). Professor Pesquisador e Subcoordenador do Programa de Pós-Graduação em Estudos do Lazer da Universidade Federal de Minas Gerais (UFMG). E-mail: < helderisayama@yahoo.com.br > . 
but without a negative bias. However, we understand this is not enough for the development of a political culture based on cultural background. The planned educational activities and carried out by research subjects need to be resized and reflected as promoters, producers and produced of culture, beyond the possibilities of entertain and delight.

Keywords: Conceptions. Leisure. Education. Integrated School Program.

\section{INTRODUÇÃO}

Ribetto e Maurício (2009, p. 148), ao traçarem o estado da arte sobre o tema educação integral e de tempo integral, constataram que a produção recente indica uma profundidade sobre essa temática e que há uma continuidade dessa produção dada pelo "crescimento do número de monografias, dissertações, artigos e comunicações". Em meados do ano de 2013, realizamos consulta à base de dados do Diretório dos Grupos de Pesquisa no Brasil do Conselho Nacional de Desenvolvimento Científico e Tecnológico (CNPQ), com o termo tempo integral ou educação integral e identificamos cinco grupos de pesquisa. ${ }^{1}$ Esses grupos se dedicam ao estudo e pesquisa sobre escola pública de tempo integral, gestão e políticas educacionais e qualidade de ensino. Estendemos a busca ao sistema de biblioteca digital da Universidade Federal de Minas Gerais selecionando as publicações do tipo artigo, capítulo de livro, livros, tese, dissertação, monografia de graduação e de pós-graduação e utilizando os termos escola integrada ou Programa Escola Integrada. Nessa pesquisa, encontramos um trabalho de conclusão de curso (TCC), uma monografia de pósgraduação e uma tese de doutorado. ${ }^{2}$

Nossa expectativa com as buscas era identificar publicações que tratassem do Programa Escola Integrada (PEI), proposto pela Secretaria Municipal de Educação de Belo Horizonte (SMED), cujos princípios são alicerçados no Programa Mais Educação que é política de indução do Ministério da Educação para incentivar a ampliação de jornada diária escolar. Entretanto, poucas publicações faziam referência a essa temática, principalmente abordando concepções de educação e lazer.

Ao considerarmos que há um esforço para a ampliação do acesso democrático à escola pública de ensino básico e que a sociedade brasileira vem debatendo e traçando experiências de expansão da jornada escolar diária, compreendemos que é importante pensar o que leva a essas ações de ampliação do tempo, que podem ser balizadas por diferentes concepções sobre a escola em tempo integral. Dessa forma, propusemos a pesquisa ${ }^{3}$ que teve como objetivo investigar a interface 
entre lazer e educação no PEI, procurando identificar e analisar as concepções de lazer e educação apropriadas pelos sujeitos responsáveis pela ação, a partir dos contextos de produção do programa.

O referencial analítico que fundamentou a pesquisa foi o ciclo de políticas (policy cycle approach) proposto por Ball (2011), que auxilia na análise da trajetória de políticas e programas educacionais, contemplando os contextos de influência, de produção de textos, de prática e de resultados / efeitos. Ao apropriarmo-nos dessas ideias, temos entendimento que as políticas apresentam constructos diferenciados que as aproximam de uma constituição por meio de regulação e de imperativos que envolvem princípios e valores e por meio de esforços coletivos em níveis de interpretação. Tais aspectos da constituição das políticas são apresentados de forma diferenciada e dependente do tempo/ espaço social e histórico. Desse modo, atribuímos à política a lógica de ciclos proposta por Ball, considerando o movimento desse campo, que é composto por lutas de valores, interesses e significados.

O ciclo de políticas é composto pelos contextos de influência, de produção de texto, da prática, dos efeitos (resultados) e da estratégia política. Com a articulação dos contextos de influência, de produção de textos e da prática, percebemos que a política não finaliza num texto legislativo e pode se materializar como uma intervenção textual. No entanto, carrega consigo possibilidades de ser reinterpretada, reinventada e recontextualizada a partir da significação dos sujeitos envolvidos em sua produção. Os contextos de efeitos/ resultados e estratégia política dizem respeito aos impactos e às interações das políticas sobre as desigualdades, considerando os aspectos de justiça, igualdade e liberdade individual.

O presente trabalho evidencia o contexto da prática do Programa Escola Integrada, objetivando a compreensão das concepções de educação e lazer nos processos de intervenção do programa. Considerando a atualidade, Ball (2011) revela que há uma transformação nos princípios da provisão social e, como isso, há mudanças nos sistemas de financiamento, nos papéis e nos estilos de administração, nas relações sociais e nas condições das organizações públicas. Assim, são construídos os discursos que servem de base para a elaboração das políticas e onde os grupos de interesses operam, buscando fortalecer seus argumentos e dar legitimidade às suas ideias. Desse modo, foram eleitas as questões para a compreensão dos fenômenos lazer e educação: quais concepções de lazer são utilizadas no programa Escola Integrada? De que maneira o lazer é tratado no PEI? Existe conexão entre as abordagens conceituais do lazer do PEI, isto é, no projeto político-pedagógico e nas ações educativas? 


\section{PROGRAMA ESCOLA INTEGRADA, LAZER E EDUCAÇÃO: A INTERVENC̣ÃO NA ESCOLA EM TEMPO INTEGRAL}

O cenário da investigação foi o Programa Escola Integrada do município de Belo Horizonte, que estabelece uma ampliação da jornada diária escolar para atender crianças e jovens matriculados nas escolas municipais de Ensino Fundamental. Sua finalidade é o atendimento prioritário aos territórios de vulnerabilidade social, com propósito de agregar o entorno da escola como espaço educativo e, com isso, possibilitar melhoria na qualidade da educação. Na educação, algumas estratégias de intervenção estatal trazem, além da desigualdade econômica, a desigualdade social como "questão de fundo", e estas norteiam os projetos e programas de governo implantados no espaço escolar para o atendimento de crianças, jovens e adultos.

No que se refere às ações, a Coordenação da Escola Integrada (BELO HORIZONTE, 2008, p. 22) relata que a carga horária ampliada tem como proposta o desenvolvimento de "atividades de diferentes áreas do conhecimento, formação social e pessoal, lazer, esportes, cultura e artes, acompanhamento pedagógico, desenvolvidas em oficinas que completam o currículo de forma a integrar as diversas dimensões formadoras do ser humano".

As ações educativas são desenvolvidas por agentes culturais e monitores universitários, a coordenação desses trabalhos é feita por um professor pertencente ao quadro administrativo da escola (professor comunitário) e aos setores centrais e regionais da SMED (coordenador geral e regional). Existem, também, um monitor e um coordenador de núcleo do Programa Segundo Tempo (PST) ${ }^{4}$, responsáveis pela oficina voltada para o esporte, monitorados por uma equipe ligada ao Ministério do Esporte. Esses atores envolvidos na execução constituíram o grupo da investigação.

De acordo com a proposta pedagógica, o Programa Escola Integrada amplia a função da escola com experiências desencadeadoras do desenvolvimento humano, social e cultural de crianças, adolescentes e jovens belo-horizontinos (BELO HORIZONTE, 2007) e propõe práticas culturais que interpretamos como atividades de lazer, as quais englobam as diversas linguagens, as manifestações e os interesses das pessoas. Considerando esse julgamento, construímos o argumento de que o PEI dá pistas de suas interfaces com o lazer e que a análise das interfaces entre lazer e educação no programa pode contribuir para o debate sobre a temática escola em tempo integral e seus processos de intervenção.

O PEI tem o Programa Mais Educação como referência para seu planejamento, tanto no que se refere ao arcabouço teórico quanto no 
apoio financeiro dado às instituições que realizam ações socioeducativas. O aporte teórico no qual o programa baseia-se é constituído de alguns macrocampos, um deles é o esporte e lazer, cuja ementa é:

Atividades baseadas em práticas corporais e lúdicas através de oficinas esportivas promotoras de práticas de sociabilidade, com ênfase no resgate da cultura local bem como o fortalecimento da diversidade cultural. No seu desenvolvimento deve prevalecer o sentido lúdico, a livre escolha na participação e a construção pelos próprios sujeitos envolvidos de valores e significados da prática dessas atividades, com criticidade e criatividade. Deve-se ressaltar o duplo aspecto educativo do esporte e do lazer; a possibilidade de educar para e pelo esporte e lazer. Isso significa o acesso ao conhecimento de novas práticas esportivas e de lazer e as reflexões resultantes dessas práticas. (BRASIL, 2009, p. 11)

Considerando esse referencial de esporte e lazer, as oficinas desenvolvidas no PEI visam "atender às demandas do universo infantil e juvenil na perspectiva de desenvolvimento de competências múltiplas e vivências capazes de proporcionar uma aprendizagem significativa sintonizada com a realidade de cada educando" (BELO HORIZONTE, 2008, p. 24).

Pensar o aspecto educativo do lazer pode sinalizar a instrumentalização para o desenvolvimento ou apropriação do lazer como objeto dos processos educativos. A primeira condição anuncia uma abordagem funcionalista/ utilitarista na qual o lazer pode ser uma ferramenta para a satisfação individual e para compensar as forças do trabalho, cujas possibilidades empobrecem as perspectivas educacionais do lazer. A segunda condição apresenta o lazer como objeto do processo de aprendizagem, e interpretamos que essa lógica permite pensar que as práticas do Programa Escola Integrada podem assumir uma força produtiva, numa relação de educação e lazer que supere a dicotomia lazer/ trabalho. Essa perspectiva exige um tratamento do lazer a partir de uma linguagem conceitual e de uma reflexão crítica sobre as manifestações e produções culturais e de outras possibilidades de vivências corporais e de educação das sensibilidades (BRACHT, 2003).

Portanto, o lazer como objeto das ações do PEI pode apresentar aos sujeitos a possibilidade de apropriar e (re)construir as diferentes formas de organização da cultura tornando possível uma reflexão/ ação na produção do currículo escolar. Isso porque o currículo é entendido como um "conjunto de ações, relações, textos e metacontextos que configuram o todo das aprendizagens escolares, dos conhecimentos e saberes que traduzem experiências significativas" (ANTUNES; PADILHA, 2010, p. 99). 
Dessa maneira, construímos a aproximação do PEI com o campo da intervenção de lazer e educação por meio de elementos constituintes do campo da cultura, inclusive as linguagens, as manifestações e as vivências. Entendemos que as concepções de lazer e educação no contexto da prática podem anunciar o PEI como possível espaço de produções e significações ou configurá-lo como o lugar da reprodução restrita e utilitarista das ações. Para que as intervenções sejam críticas, acreditamos que ferramentas pedagógicas que potencializem os processos educativos devem subsidiar a mediação no campo da cultura e, com isso, transformar as experiências do PEI.

Melo (2006) resume o compromisso político-pedagógico da educação para e pelo lazer na mediação chamada de animação cultural, cuja proposta não se restringe a um campo de intervenção (pode ser implementada no âmbito da escola, do lazer, da família e demais esferas) e não deve ser compreendida somente como uma área de conhecimento. Ao considerarmos a animação cultural como uma ferramenta pedagógica para as ações educativas do PEI, queremos afirmar que percebemos que o contexto da prática do programa estabelece uma relação significativa com a dimensão da cultura, sendo reconhecido como campo de intervenção pedagógica. Assim, entendemos que a atuação dos educadores do PEI, alicerçada em concepções democráticas e emancipatórias de lazer e educação, contribui para a formação cidadã porque trata de proporcionar às crianças e aos jovens a possibilidade de intervir na formação integral.

\section{A CONSTRUC̣ÃO DOS PROCEDIMENTOS METODOLÓGICOS DA PESQUISA}

O percurso empírico iniciou no encontro com a coordenação geral do PEI na SMED, quando a proposta de trabalho foi apresentada para apreciação. Naquele momento, foram disponibilizados os documentos referenciais do programa e o aval para a realização do estudo em uma das escolas municipais da cidade de Belo Horizonte, condicionada à anuência de seus gestores. A investigação focalizou o programa buscando compreender como os fenômenos lazer e educação eram tratados, utilizando-se de estudo do caso do PEI em uma escola municipal por meio de entrevistas e registros do campo.

A escola estudada localiza-se numa região de Belo Horizonte que apresenta alto índice de vulnerabilidade, e, com a anuência dos gestores para a realização da pesquisa e o parecer favorável do Comitê de Ética em Pesquisa da UFMG, iniciamos as visitas ao Programa Escola Integrada. Imergir no campo por meio da aceitação das pessoas envolvidas na execução do PEI favoreceu para que fossem 
criados vínculos de respeito e confiança, que facilitaram a presença dos pesquisadores no cotidiano das oficinas. Os vínculos estabelecidos possibilitaram divisar aspectos significativos para a elaboração do roteiro dos instrumentos da pesquisa. O acompanhamento de cada oficina promoveu uma aproximação com os sujeitos, que, esclarecidos dos objetivos da pesquisa, prontificaram-se a participar dela assinando o Termo de Consentimento Livre e Esclarecido (TCLE).

As questões da entrevista foram elaboradas de forma diferenciada de acordo com as especificidades das atribuições para alcançarem as reflexões do entrevistado (agente cultural, professores, coordenadores e monitores universitários). O roteiro de investigação foi estruturado, mas não foi considerado como algo estático, assim, no processo interativo com alguns entrevistados, surgiram temáticas, cujas abordagens foram necessárias para a compreensão da realidade empírica. Com o foco nos objetivos da pesquisa, as demais questões elaboradas no processo dinâmico da entrevista tiveram como objetivo expressar compreensão do discurso, esclarecer e retomar a temática ou aprofundá-la (SZYMANSKI, 2010).

As entrevistas foram realizadas com 14 sujeitos, sendo professora comunitária (C1), coordenadora geral (C2), coordenadora regional (C3), dois coordenadores de núcleo PST (C4 e C5), quatro monitores universitários (MU1, MU2, MU3 e MU4) e cinco agentes culturais (AG1, AG2, AG3, AG4 e AG5).

A análise do material qualitativo possui, dentro da proposta de investigação social, a finalidade heurística de inserção no contexto da descoberta, examinar os dados por meio do balizamento entre os achados e os pressupostos e ampliar a compreensão dos contextos culturais (BARDIN, 2008). Esse apontamento conduziu a definição da análise de conteúdo na modalidade temática (MINAYO, 2010) para a compreensão dos significados no contexto da fala dos investigados.

\section{O PROGRAMA ESCOLA INTEGRADA E EDUCAC̣ÃO: CONCEPC̣ÕES NO CONTEXTO DA PRÁTICA}

A proposta pedagógica do Programa Escola Integrada sugere que as intenções dessa intervenção política são o enfrentamento da crise do fracasso escolar, revelado pelos índices de avaliação de rendimento e de fluxo (aprovação, repetência e evasão) dos alunos. Tais textos, produtos e produtores das orientações do programa, anunciam uma concepção de educação como direito de cidadania, como processo de escolarização ditado pelo acesso e permanência 
e como um processo que envolve experiências para além do conhecimento sistematizado no currículo escolar tradicional.

De um modo geral, as legislações brasileiras (constituição e leis educacionais) estabelecem a educação como um direito, isso é indiscutível. Pensar que a educação se traduz somente no acesso e permanência é restrito, pois isso é condição fundamental para o processo de escolarização. Para abarcar uma discussão conceitual ampla, é necessário refletir a função da escola e o papel dessa instituição na/ para a sociedade. É preciso, ainda, reconhecer que o espaço escolar é uma das esferas possíveis, e não única, de aprendizagem e estabelece vínculos com a cultura.

Boto (2006) narra que o direito subjetivo de ir à escola e as reformas de métodos, tornando a escola mais atrativa, foram os primeiros constituintes do direito à educação escolarizada. Além disso, surge, no século XXI, o direito de ter os conteúdos curriculares alterados, dando ênfase à diversidade, à pluralidade cultural, às minorias sociais, às questões ambientais e possibilitando a desconstrução do modelo dos espaços, tempos e saberes curriculares.

Ao longo do processo de investigação, foi possível perceber que alguns sujeitos envolvidos no Programa Escola Integrada mostramse capazes de entender a necessidade de um olhar diferenciado para a organização curricular da escola.

A princípio eu achava que o conhecimento conteudista era muito importante. E a gente tinha
mesmo que se preocupar com a matéria, eu era daquelas professoras que eram chatas, que
cobrava o conteúdo o tempo inteiro. Agora, não acho que é tão importante assim. Eu acho
que os outros conhecimentos agregam mais a personalidade, o caráter do que o conteudista.
Então, mas isso aí foi só quando eu entrei para o programa. É que mudou minha visão em
relação ao conteúdo e a importância de somente o conteúdo. (Entrevistado C3)

Esse entendimento é necessário para a desconstrução de organizações curriculares tradicionais, porém não é suficiente para as mudanças significativas da ação. Consideramos que a forma também é conteúdo, isso significa que um conhecimento diferenciado ou inovador pode vir a ser enquadrado na mesma moldura tradicional em função da forma como é trabalhado. Se o conteúdo é educativo, a forma como são desenvolvidas as atividades apresenta possibilidades pedagógicas.

As experiências do programa podem legitimar-se apenas como instrucionista, subjugando o caráter educativo das práticas.

O objetivo é desmistificar essa coisa do futebol. Eu tento sair do futebol, porque eu acho que se não for aqui, eles não vão vivenciar outros esportes. E vai crescer um menino que não conhece o esporte, sabe. Pode até sair daqui um menino que se interesse por aquilo e crie gosto por outro esporte. Não sei, mas a gente tem que mostrar para eles que tem outras vivências, eles têm que conhecer. (Entrevistado C4) 
Entendemos que o caráter instrutivo e informativo é parte do processo de aprendizagem, porém não deve ser o único. O esporte tem aceitação, praticamente, generalizada entre as pessoas e caracteriza-se como interesse cultural do lazer. Portanto, os profissionais devem ir além de apresentar outra modalidade esportiva e estimular a prática. É preciso contextualizar essa prática no cenário contemporâneo, buscando atribuir-lhe novos significados e olhares.

Essa lógica supera a concepção de educação que se baseia numa organização de conhecimentos a serem transmitidos, denominados de conteúdos, que são depositados no aluno para serem aprendidos. Entendemos que a educação não deve se resumir na instrução, que é oferecimento de aparatos básicos para que o aluno se relacione satisfatoriamente com a sociedade e com seu mundo, pois isso não é suficiente para a aptidão de relacionar-se com o mundo e com a sociedade de maneira plena, autêntica e satisfatória (GALLO, 2008).

Há trechos nas falas dos sujeitos que demonstram uma visão da escola como espaço de instrução, de apropriação de conteúdo externo ao aluno.

Tento passar para eles os ensinamentos, igual converso com meus filhos. É o que estou tentando com meus alunos, mas eu nem falo aluno e falo meus meninos. Essa palavra aluno, deixo para a escola regular, falo meus meninos $\mathrm{Na}$ Escola Integrada você pode variar, pode criar a forma que vai trabalhar, pode escolher o que trabalhar. E na escola regular você tem aquelas regras de dar isso porque seu conteúdo programado foi esse. Aqui não, aqui você trabalha com eles assim. Uma pessoa até me disse que a escola não é integrada. (Entrevistado AG5)

Essa visão contribui para reforçar a escola como espaço de ensino, sugerindo o binarismo de tempo para instrução e tempo para outras possibilidades educativas, o que não compactua com a ideia de escola em tempo integral. Evidenciamos, como um dos fatores que contribuem para essa dicotomia, a carência de planejamento coletivo que articule todas as ações educativas propostas no ambiente escolar.

O planejamento depende. Nós temos três tipos de profissionais. Nós temos o pessoal do Segundo Tempo, eles planejam aqui, têm o acompanhamento deles, tudo separado. Nós temos o PIP, que é projeto de intervenção pedagógica, toda sexta-feira planejam lá com as acompanhantes deles. Nós temos também, os estagiários de faculdade. Eles também fazem o planejamento na faculdade. Mas, nós temos um caderno de planejamento aqui, que tudo que eles planejam lá, eles têm que me apresentar. Entendeu? (Entrevistado C1)

Compreendemos por meio das entrevistas que, mesmo sendo incipiente a aproximação entre as ações pedagógicas exercidas nos tempos diferenciados da jornada escolar, existe a estratégia para relacionar as intervenções a partir da coordenação. Os 
coordenadores das diversas atividades pedagógicas que acontecem sob a responsabilidade da instituição são responsáveis pela construção do diálogo entre as diferentes propostas de intervenção. Essa é uma possibilidade de construir vínculos entre as ações educativas e a proposta político-pedagógica da instituição.

Segundo Antunes e Padilha (2010), o planejamento dialógico enfatiza valores culturais e políticos contextualizados e com base numa visão interdisciplinar de ação. A ação de planejar coletivamente significa tomar decisões em conjunto, a partir do conhecimento da realidade e priorizando as aprendizagens e a garantia de direito aos processos educativos qualificados. Um planejamento escolar deve considerar a articulação do saber científico com o saber técnico, cultural, filosófico, artístico (GADOT'TI, 2009), sendo a representação de currículo escolar que expresse a realidade local, a cultura e os saberes produzidos socialmente.

Para além desse planejamento, as entrevistas também permitiram perceber que algumas situações levam a uma limitação do planejamento das ações do programa. Um fator limitante apontado pelo entrevistado AG2 foram as estratégias de ajustamento para cobrir a falta de outros educadores no cotidiano do PEI. Interpretamos que a falta do planejamento da ação, por mais que se considerem as experiências profissionais, aproxima a intervenção à improvisação e ao imediatismo na resolução dos desafios. Corroboramos Antunes e Padilha (2010, p. 80) ao definirem que "realizar planos e planejamentos educacionais ou escolares significa exercer uma atividade engajada, intencional, científica, de caráter político e ideológico e isento de neutralidade".

As situações experienciadas no contexto da prática podem ser promotoras e promulgadoras de novas reflexões e mudanças que serão fortalecidas na expressão e na manifestação do coletivo de atores envolvidos diretamente nas ações. Esses sujeitos são fundamentais para anunciarem novas possibilidades e avaliações do Programa Escola Integrada. Barreto e Lopes (2010) relatam que, nesse contexto, são produzidos efeitos e consequências que interferem na proposta original, promovendo mudanças e transformações significativas, pois é nele que a política está sujeita à interpretação e à recriação.

Nesse sentido, as concepções de educação dos sujeitos da prática podem contribuir para uma reflexão, debate e transformação do uso da ampliação do tempo escolar. As concepções expressas pelos sujeitos podem ser ressignificadas e alicerçar novos rumos para a organização dos tempos escolares.

Educação é muito mais que sentar na sala de aula e passar conbecimento. Acho que 
educação é a vida, mesmo. É viver junto, na medida em que estar com o outro você está educando e sendo educado. (Entrevistado C2)

Educação é, a gente vê que muitos meninos não vêm com aquela educação de casa. Não é que a gente vai conseguir mudar tudo que ele traz de casa, mas no momento que eles estão aqui aprendem muito. Tem vez que em casa não recebe nem um bom dia, ai quando a gente dá um bom dia para ele, é um tipo de educação que eles estão recebendo. Ai a gente dá um bom dia, eles abrem aquele sorriso maravilhoso. Educação não é só educar dentro da escola. Na rua, também, ele cumprimentar, sempre respeitando os colegas, os outros meninos. (Entrevistado AG1)

Nas falas dos diversos profissionais que atuam no programa é possível perceber que as concepções de educação indicam diretrizes para o trabalho, convivência e comportamentos/ hábitos. Esses elementos são insuficientes para garantir a educação em sua amplitude, que significa considerar o processo de produção cultural e de constituição de autonomia para o exercício da cidadania. Porém, a expressão dos sujeitos não é o único aspecto que constitui o contexto da prática, ou seja, as questões relacionadas à gestão escolar, à materialidade, à territorialidade também são constituintes. A escuta dos sujeitos evidenciou a dificuldade imposta pela gestão escolar para a aquisição de materialidade e disponibilização de espaços para executar as ações do programa, o que foi percebido como negativo pelo entrevistado MU3.

As entrevistas forneceram pistas para a compreensão de que a escola em tempo integral exige também uma estrutura organizacional e operacional, que potencializa as ações educativas e possibilita condições favoráveis para o posicionamento e comprometimento dos profissionais em relação ao programa. Compartilhamos com Gallo (2008, p. 17) a ideia de que nas práticas do contexto microssocial o aluno é "levado a assumir posturas de liberdade, respeito, responsabilidade", ao mesmo tempo em que observa essas mesmas práticas nos sujeitos envolvidos na ação.

O debate conceitual e a construção de ações coletivas são fundamentais para materializar no espaço escolar um processo de formação amplo e qualitativamente significativo.

\section{O LAZER NA ESCOLA INTEGRADA: 0 QUE PENSAM OS SUJEITOS DA AÇÃO?}

O lazer carrega marcas da cultura na qual se insere ao mesmo tempo em que pode acionar movimentos e mudanças (PARAÍSO, 2010), dessa forma, as práticas de lazer podem ser produtoras de novos significados para a cultura. Portanto, é necessário considerar as construções conceituais de lazer apropriadas pelos sujeitos que atuam na escola para compreender suas práticas. 
Paraíso (2010) esclarece que as práticas de lazer devem ser miradas como textos culturais e, ao investigá-las, deve-se observar o que é ensinado, preservado e divulgado. Nesse sentido, as práticas são compreendidas como artefatos culturais "divulgadores e produtores de cultura" (PARAÍSO, 2010, p. 35).

Corroborando Marcellino (2010), julgamos que algumas considerações são essenciais para a investigação das "leituras" que os sujeitos da ação fazem do lazer, pois auxiliam-nos a evidenciar suas interpretações. Essas considerações indicam o lazer como cultura vivenciada (praticada, fruída ou conhecida) dos diversos conteúdos culturais, como fomentador de questionamentos referentes à sociedade, como tempo privilegiado para as vivências e portador de aspectos educativos. Ademais, o lazer envolve as possibilidades de descanso, divertimento e/ ou de desenvolvimento pessoal e social, conforme aponta o autor.

Alves Júnior e Melo (2003) afirmam que, na construção histórica do lazer, o descanso e divertimento estiveram presentes, por vezes, como objetivo das reivindicações da classe trabalhadora. $\mathrm{O}$ descanso e divertimento podem ter a função, na lógica do trabalho, de recuperação de forças ou compensação e de instrumento de controle, por meio de atividades direcionadas.

Algumas interpretações dos sujeitos sobre o lazer carregam os elementos diversão e distração, o que nos leva a refletir sobre o fenômeno.

Acho que a partir do momento que chego pra dar uma aula para os alunos, e eles durante
a atividade estão se distraindo, isso a gente vê até na própria expressão facial, eles rindo,
brincando, jogando e tudo mais, é através disto. Quando você monta uma aula, o aluno
consegue fazer e ele gosta e participa, ele dá o feedback positivo pra você dizendo que
a aula foi bacana, foi boa, que gostou demais, ele se divertiu durante meu trabalho.
(Entrevistado C5)

Entendemos que as funções de divertimento e descanso permeiam as construções conceituais de lazer, principalmente, por influências e contrapontos do mundo do trabalho e das obrigações. Entretanto, a concepção de lazer fundada somente nesses dois elementos torna-se restrita e simplista, visto que outras especificidades devem ser contempladas para balizar os processos de intervenção.

No contexto da prática, foi possível elencar outros constructos de lazer relevantes para o entendimento das ações realizadas. $\mathrm{Na}$ fala dos atores foi anunciada possível interface entre lazer e o programa quando anunciado que suas ações podem estar relacionadas com o currículo escolar, na perspectiva da interação com "as disciplinas e com o lúdico" (Entrevistado MU2). Essa narrativa anuncia a possibilidade de construção de um currículo aberto às outras possibilidades de 
seleção, organização do conhecimento e de trato do lúdico, como potencializador das experiências e aprendizagens.

O lúdico contribui para a construção das concepções de lazer e sua compreensão revela-se como ponto de referência nas discussões sobre o lazer no contexto brasileiro. No entanto, apesar do uso recorrente do termo associado ao lazer, há uma imprecisão de significado com que se utiliza a palavra (MARCELLINO, 1990; BRACHT, 2003).

Gomes (2004, p. 145) define o lúdico como "expressão humana de significados da/ na cultura referenciada no brincar consigo, com o outro e com o contexto". Bracht (2003) revela que, além dos aspectos tempo, atitude, busca do prazer, o caráter lúdico das práticas é uma das características do lazer, apropriado na dimensão da cultura. Nesse sentido, compreendemos que nas ações da Escola Integrada pode haver a interação entre o sujeito e a experiência oportunizada nas práticas culturais e suas manifestações (corporal, oral, escrita, artística, gestual, visual), o que caracteriza o lúdico.

Entre os sujeitos entrevistados, há recorrência em formar conceito acerca do lazer a partir da adjetivação da prática como lúdica e prazerosa. Essa lógica é identificada na explanação de um dos entrevistados que revela que lazer é o que leva ao prazer, à satisfação pessoal, como "ler dá prazer, é lazer; se jogar bola é bom, é prazeroso, é lazer para mim” (Entrevistado MU3).

Nesse contexto, é possível perceber o imaginário de que lazer é prazer, tal perspectiva empobrece as potencialidades dolazer, retirando dele a substantivação e torna-o adjetivo de outras dimensões da vida humana. Segundo Melo e Alves Júnior (2003), definir, isoladamente, que lazer é prazer é um equívoco, mesmo que a prática seja prazerosa. Essa adjetivação não constitui uma exclusividade das práticas de lazer e estas não resultam, necessariamente, nesse sentimento. $\mathrm{O}$ desdobramento dessa abordagem pode indicar a caracterização de outras dimensões da vida como práticas de lazer.

No contexto da prática, algumas entrevistas anunciam a relação estreita entre lazer e trabalho.

Lazer é eu estar produzindo alguma coisa com praz̧er, com alegria, com satisfação, eu estou no lazer. Ai, a hora que eu estou lá até de madrugada fazendo uma lista, eu já fiquei até duas horas da madrugada, é lažer. Porque eu estou fazendo com praz̧er, com motivação. Então, é tudo aquilo que eu faço com motivação, com alegria, com prazer, eu creio que é lazer. As vezes, eu estou capinando, mas é com prazer que faço aquilo, né. Varrendo um passeio, mas com prazer porque quer ver aquilo limpinho. Então lazer é pražer, passa por aí. (Entrevistado C1)

Compartilhamos com Meloe Alves Júnior (2003) o entendimento de que trabalho e lazer apresentam características diferentes. Os dois 
se constituem como dimensões da vida humana que se relacionam e deveriam proporcionar prazer, mas apresentam especificidades próprias. Marcellino (2008) aponta que o lazer restrito à atitude fortalece a dependência exclusiva da relação sujeito/ prática. A partir dessa dimensão individual qualquer atividade que contemple as características de escolha e níveis de satisfação e prazer é tratada como lazer.

Ressaltamos que as dimensões da vida estão inter-relacionadas dialeticamente na dinâmica social, dificultando a demarcação de fronteiras entre o lazer e as obrigações cotidianas. Além disso, a definição de lazer apenas como prazer pode restringir os processos de avaliação das ações, pois limita-se à observação de sensação resultante da prática e à aceitação de determinadas intervenções pedagógicas.

Entretanto, dentre coordenadores, monitores e agentes culturais entrevistados, foi possível identificar interpretações diferenciadas acerca da relação lazer/ prazer, indicando o aspecto tempo.

\begin{abstract}
Eu curto muito o que faço. Quando eu posso, entro na quadra com os meninos, eu brinco, eu completo o time, mas sempre levo pro lado mais profissional. É diferente do domingo, fim de semana, pegar minha chuteira e ir para uma quadra e bater bola e brincar com os amigos. Lá eu estou me divertindo, aqui eu tenho outra função, porque no mesmo tempo que estou brincando com eles, eu estou de olho para que eles não briguem, não falem palavrão, não agridam o outro e para que eles aprendam. (Entrevistado C5)
\end{abstract}

O aspecto constituinte do lazer é referido por esses sujeitos como um tempo livre/ liberado possível para o descompromisso, a falta de seriedade em contraposição ao tempo das obrigações (profissional e escolar). Como profissionais que atuam no âmbito do lazer, eles devem ter clareza que suas ações de trabalho são atividades de lazer para o outro, portanto exigem uma postura profissional mesmo que as resultem em prazer para todos os envolvidos. Marcellino (2008) afirma que o tempo de lazer não se opõe e, sim, relaciona-se ao tempo das obrigações, sobretudo ao trabalho. Porém, os contrapontos foram identificados nas manifestações dos sujeitos entrevistados.

O cuidado necessário à contraposição de lazer e trabalho é o de considerar que processos de alienação podem acontecer nessas esferas. Com isso, o tempo dedicado à atividade de lazer ou trabalho deve propiciar percepções e posicionamentos críticos a respeito dos valores que perpassam essas vivências. Essa argumentação contribui para pensar o espaço da escola como lócus de trabalho e de lazer, onde esses elementos podem contribuir para mudanças culturais e, consequentemente, propiciar questionamentos sobre a ordem social.

Outro posicionamento interessante nas interpretações dos agentes culturais é o olhar para o tempo da escola como momento de 
"levar a sério", em oposição ao tempo de distração. "Ocupar o tempo deles com lazer, com jogos, porque aqui não é uma escola igual lá na outra escola. Isso aqui é uma coisa que ele vem para distrair. Distrair as mentes deles" (Entrevistado AG1).

Distrair-se, divertir-se, entreter-se são possibilidades atribuídas ao lazer, essas intenções não impedem que as práticas assumam características pedagógicas e educativas. Não é possível também negar que esses elementos se relacionam às especificidades do universo escolar.

Torna-se necessária uma compreensão que considera as atividades de lazer como práticas culturais, ou seja, que carregam, também, "um conjunto de valores, normas e princípios que regem a vida em sociedade" (MELO; ALVES JÚNIOR, 2003, p. 39). Dessa forma, o lazer é representado como processo de participação e produção cultural, suplantando a noção de conteúdo/ produto a ser transmitido. Nas falas dos sujeitos que coordenam as ações do Programa Escola Integrada, foi possível identificar diferentes compreensões de lazer, que, às vezes, se inter-relacionam ou se contrapõem. Uma ideia comum entre eles é que há um potencial educativo nas vivências possibilitadas pelo programa.

A partir desses argumentos, evidenciamos a importância do aspecto educativo do lazer para uma formação cultural que permita, aos envolvidos, ampliar os olhares para o mundo e perceber-se como sujeito. Alves Júnior e Melo (2003) reconhecem a necessidade de considerar o duplo processo educativo do lazer, cujos significados são o aproveitamento do potencial das atividades para trabalhar valores, condutas e comportamentos (educação pelo lazer) e a configuração do lazer enquanto objeto para o qual as ações são especificadas (educação para o lazer).

Marcellino (1987, p. 84) ressalta a escola como agência de educação para o lazer na medida em que apresenta um papel preponderante como "mediadora" entre culturas. Nessa perspectiva, compreendemos a escola como espaço significativo para o reconhecimento de identidades, apropriação e produção cultural e percebemos a relação lazer e educação, nesse universo, por meio da interseção com a cultura.

Nessa lógica, o lazer como veículo de educação é uma das dimensões do processo educativo, mas não deve ser única e nem isolada. A prática de lazer não deve se configurar numa possibilidade de ocupação de tempo, consumismo ou no tarefismo, cujos efeitos podem direcionar para vivências alienantes e reprodutoras de uma ordem social estabelecida. O lazer, como processo educativo, exige também 
outras condições de envolvimento na atividade, o que torna possível a constituição do sujeito crítico. A prática educativa deve proporcionar o saber como possibilidade de constituição do sujeito e dar conta de abordar as identidades, as representações sociais e seus significados.

As práticas educativas de lazer da Escola Integrada são apresentadas de forma ampliada pelos seus coordenadores, extrapolando os muros da escola.

Porque além de você oportunizar aos meninos conhecerem sua própria cidade, os jovens de periferia têm muita dificuldade de ir ao parque central. Muitos dos nossos meninos aqui da periferia não conhecem o parque municipal. Primeiro pela dificuldade de ir, e quando vai só atravessa o parque para ir à região hospitalar. Eles não têm a oportunidade de brincar naqueles brinquedos. (Entrevistado C2)

$\mathrm{Na}$ perspectiva dos coordenadores, as práticas de lazer fomentam oportunidades de conhecer, usufruir e incluir, e a cidade assume um caráter educativo. Entendemos que a escola e a cidade são esferas públicas de aprendizagem, porém apresentam as especificidades da cultura escolar e urbana. Extrapolar os "muros da escola" sugere redimensionar suas práticas culturais e as relações sociais de uma cultura escolar que seleciona e hierarquiza saberes.

Vago (1996) retrata que a cultura escolar e a urbana de Belo Horizonte foram constituídas em dois universos culturais e duas cidades distintas: moderno e antigo, urbano e suburbano. Nesse cenário, havia a tensão entre as práticas culturais da rua, da cidade e da escola e suas possíveis interpenetrações. Nesse sentido, pensar sobre a cidade e a escola requer debater sobre as relações pedagógicas estabelecidas nesses dois contextos, cujo foco, para além do conhecer e fruir, deve estender-se para o exercício de produção de conhecimento, apropriação e pertencimento à cidade.

Corroboramos Vago (2009, p. 26) que a escola é "um lugar de culturas, um lugar das culturas e um lugar entre as culturas" e possui uma organização própria. Entendemos que a escola, em sua peculiaridade, relaciona-se com outras esferas formativas na dinâmica social. Nesta investigação, essa relação se materializa nas ações propostas pelo Programa Escola Integrada. Nesse sentido, compreendemos que é necessário analisar e compreender as condições de transformação da educação e lazer, imbricadas nos limites e potencialidades do programa.

\section{A INTERFACE LAZER E EDUCAÇÃO: UM CAMINHO POSSÍVEL}

Com o intuito de entender as relações estabelecidas entre lazer e educação no Programa Escola Integrada, nosso olhar direciona 
para as concepções que permeiam as práticas pedagógicas e, a partir daí, compreender a lógica que legitima as vivências proporcionadas. Entendemos que a escola e seus programas se relacionam com as dinâmicas sociais e que, por meio deles, os sujeitos podem construir formas de relacionar-se com o mundo e produzir significados. No caso da escola em tempo integral, assumimos como princípio que

Para formar integralmente o aluno não podemos deixar de lado nenhuma dessas facetas: nem a sua instrumentalização, pela transmissão de conteúdos, nem sua formação social, pelo exercício de posturas e relacionamentos que sejam expressão da liberdade, da autenticidade e da responsabilidade. A esse processo global podemos, verdadeiramente, chamar de educação. (GALLO, 2008, p. 17)

Nesse sentido, é necessário compreender como os sujeitos que atuam no PEI percebem o programa e sua função, pois é o indicador de qual educação e lazer julgam essenciais para a formação dos alunos.

Não vou falar momento de lazer, mas seria uma segunda oportunidade para os meninos não estarem na rua fazendo outras coisas. Poderiam estar na rua fazendo outros tipos de coisas, mas na Integrada estariam fazendo oficinas. Estariam conhecendo outras realidades das coisas. Por mais que eles não gostem de certas coisas, mas ali estariam tendo vivências. (Entrevistado MU4)

Aqui funciona como um espaço onde o pai pode deixar o filho e ter a tranquilidade de saber que ele vai ser vigiado, orientado, que não vai estar solto e sozinho. Ele sai para trabalhar, fica fora 8 horas, mas sabe que o filho está aqui. (Entrevistado AG5)

No contexto apresentado, um apontamento interessante na compreensão dos entrevistados sobre o programa aponta para o cuidado e proteção das crianças e jovens atendidos. Por certo, na dinâmica social, a escola sofre influências que afetam seu papel educativo, porém considerar os problemas presentes no contexto social não significa eliminá-los por meio da escola em tempo integral. Cavaliere (1999) aponta que, no caso de famílias de classe economicamente desfavorecidas, são aumentadas suas necessidades e expectativas em relação à escola pública. As mudanças de costumes e valores, a reorganização familiar e a disseminação do trabalho feminino contribuem para aumentar as dificuldades no exercício do papel educativo. Portanto, é preciso analisar se a ampliação da função da escola significa "reforçar o controle social, ou dependendo de como se organize e também de sua tradução curricular, servir ao desenvolvimento democrático e aos interesses de emancipação?” (CAVALIERE, 1999, p. 117).

É essencial uma formação política dos sujeitos que incite uma postura crítica ante os desafios sociais. Gadotti (2009) aponta que não basta matricular o público pobre na escola (inclusão), é preciso 
incluir sua cultura, seus desejos e projetos de vida. Assim, a educação deve formar para e pela cidadania, promover o exercício dos direitos, abrindo espaços para a participação e formação política e social.

No caso do PEI, assumir que a educação e o lazer têm a finalidade exclusiva ou primordial de manter os alunos incluídos socialmente determina uma estratégia de embate de problemas sociais, porém esse fim não pode mascarar ou encobrir as causas das mazelas sociais. A ação coordenada e executada pelos sujeitos da pesquisa deve refletir uma perspectiva política, que transcende o cuidar e assistir no caminho da conquista e garantia de direitos.

Demo (2011) afirma que embora a assistência seja necessária para a garantia da sobrevivência, é insuficiente. É possível pensar em "políticas emancipatórias, que unam inserção ao mercado e ao mundo da cidadania organizada" (DEMO, 2011, p. 74). Compartilhamos com o autor a visão de que a "pobreza material" não é mal menor, porém a "pobreza política" possui uma face "comprometedora e destrutiva" (p. 19).

Assim, compreendemos que a análise da ação educativa no Programa Escola Integrada, executada pelos coordenadores PST, monitores universitários e agentes culturais, dá pista da constituição política dessa prática.

A gente perceber os limites, obedecer as regras que são impostas. Certas ou erradas na
percepção da pessoa, mas são impostas pela sociedade. E, infelizmente, a gente tem que
cumprir as regras colocadas, seja no município, seja no Estado, em qualquer lugar. Isto
tudo para mim é educaşão. Então, os meninos estarem aqui comigo, estarem na educação
física escolar, eu estou educando-os a terem regras e cumprirem regras lá na frente, a cumprir
os limites. A aprender a ganhar ou a perder, a não ser sempre o primeiro, ser maleável, a
conversar e chegar num meio termo. (Entrevistado C4)

Segundo Gallo (2008, p. 20), a educação sempre esteve permeada pelos mecanismos de controle, e a disciplinarização indica tanto o controle sobre o aprendizado "o quê, quando, quanto e como o aluno aprende", quanto o domínio sobre o próprio aluno. O lazer, em sua constituição histórica, também esteve marcado por ajustamento dos sujeitos à conduta posta por regras institucionais (escola, família, trabalho, mercado, mídia) (GOMES; PINTO, 2009). Essas concepções articulam o aprendizado ao domínio, ou seja, as práticas são impostas e carregam valores determinados por quem detém o poder.

Dessa forma, é possível inferir que a escola em tempo integral necessita desconstruir, além da hierarquização de saberes científicos (denominados como disciplina curricular), precisa discutir as questões que se relacionam ao poder. Nesse caso, a disciplina diz respeito à aprendizagem e também ao comportamento, "disciplinar o aluno 
é também fazer com ele perceba seu lugar social" (GALLO, 2008, p. 20). As práticas sociais e culturais podem refletir uma tradição alienante ou produzir uma cultura política, necessária à construção de uma política cultural. Para tal, os discursos coercitivos dos sujeitos devem ser desconstruídos e suas ações devem refletir uma mediação no campo da cultura. Melo (2006, p. 23) revela que a "política da cultura deixa de ser secundária, a olhos vistos ocupando papel central nas tensões que permeiam a manutenção da ordem social".

Giroux (1992) retrata que uma política cultural requer o desenvolvimento de uma pedagogia que esteja atenta às histórias, sonhos e experiências que os alunos inscrevem na escola. E somente por essas formas subjetivas os educadores "poderão desenvolver uma linguagem e um conjunto de práticas que confirmem e engajem a natureza contraditória do capital cultural que constitui o modo como os estudantes produzem significados que legitimam formas específicas de vida" (GIROUX, 1992, p. 96).

Nessa circunstância, é preciso ressaltar que é por meio das experiências articuladas à transmissão/ instrução, fruição e produção de cultura que educação e lazer tornam-se constituintes dos sujeitos capazes de pensar e intervir no seu entorno e na dinâmica social. Nesse sentido, os sujeitos entrevistados que atuam no PEI levam para o programa uma concepção de educação e lazer, cuja dimensão pode ser reformulada naquele espaço. Neste, é possível uma interferência de uma cultura escolar tradicional ou de acepções construídas a partir das experiências em projetos sociais.

\section{CONSIDERAC̣ÕES FINAIS}

O Programa Escola Integrada apresenta interfaces entre lazer e educação no universo da cultura. Compreender essa relação é necessário para ressignificar as práticas do programa, o qual pode sinalizar para o caráter de "aluno em tempo integral" ou a simplificação do tempo a partir da ocupação com atividades em si. Enquanto princípio norteador de currículo escolar, a educação e lazer concebidos somente a partir da categoria tempo podem se configurar como ocupação integral do tempo do aluno.

A escola em tempo integral precisa ser entendida como uma política pública e não como um projeto especial, pois este não garante a universalização, a democratização, o desenvolvimento de todos os sujeitos do interior da escola e, consequentemente, a ideia de cidadania. Na construção do estudo, enfatizamos que, para que as ações resultem em intervenções críticas, é preciso que o processo 
de formação profissional seja pautado em princípios que reflitam politicamente, intelectualmente, cientificamente e socialmente em luta e tensão do reconhecimento da diversidade e diferença cultural. Considerando também que a história de vida do sujeito/ ator social é importante para refletir as/ nas ações educativas do programa.

Desse modo, a formação dos sujeitos envolvidos no Programa Escola Integrada deve sustentar-se numa base indissociável de teoria e prática, ou seja, a formação técnica operacional associada à política intelectual. Assim, o processo de intervenção deve possibilitar a ampliação do capital cultural, numa perspectiva de estabelecer uma cultura política. As propostas de ação no âmbito do lazer que concebem a cultura permitem (re)construir, (re)dimensionar significados recebidos ou produzidos por uma sociedade; cuja relevância é o enfrentamento e o debate sobre a construção do lazer, da educação e da escola desejada.

\section{REFERÊNCIAS}

ANTUNES, Ângela; PADILHA, Paulo Roberto. Educação cidadã, educação integral: fundamentos e práticas. São Paulo: Editora e Livraria Instituto Paulo Freire, 2010.

BALL, S. J. Intelectuais ou técnicos? O papel indispensável da teoria nos estudos educacionais. In: BALL, S. J. Políticas Educacionais: questões e dilemas. São Paulo: Cortez, 2011. p. 78- 99.

BARDIN, L. Análise de conteúdo. 19. ed. Lisboa, Portugal: Edições 70, 2008.

BARRETO, Edna Abreu; LOPES, Alice Casemiro. Os contextos da política de currículo: a experiência da Escola Cabana (1997/2004). Práxis Educativa, Ponta Grossa, v. 5, n. 2, p. 139148, jul.-dez. 2010. Disponível em: < http://www.periodicos.uepg.br>. Acesso em: 10 mai. 2014. BELO HORIZONTE. Secretaria Municipal de Educação - SMED. Arranjos Educacionais possíveis para a Educação Integral. Salto para o futuro, ano XVIII, boletim 13, p-26-29, ago. 2008.

BELO HORIZONTE. Secretaria Municipal de Educação - SMED. Projeto Escola Integral. Belo Horizonte: Secretaria Municipal de Educação/ Prefeitura Belo Horizonte, 2007. 15 f. (Impresso).

BOTO, Carlota. Um credo pedagógico na democracia escolar: algum traçado do pensamento de John Dewey. Educação, Porto Alegre, ano XXIX, n. 3 (60), p. 599-619, set./dez. 2006. Disponível em: <http://revistaseletronicas.pucrs.br/ojs/index.php/faced/article/ view/495>. Acesso em: 17 jul. 2014.

BRACHT, Walter. Educação Física escolar e lazer. In: WERNECK, C. L.; ISAYAMA, H. F. (Org.). Lazer, recreação e Educação Física. Belo Horizonte: Autêntica, 2003. p. 147-172.

BRASIL. Ministério da Educação - MEC. Manual de Educação Integral, 2009. Disponível em: <ftp://ftp.fnde.gov.br/web/pdde/ manual_pdde_2009_escola_integral.pdf>. Acesso em: 28 abr. 2011.

CAVALIERE, Ana Maria. Uma escola para a modernidade em crise: considerações sobre a 
ampliação das funções da escola fundamental. In: MOREIRA, A. F. B. (Org.). Currículo: políticas e práticas. Campinas: Papirus, 1999. p. 115-129.

DEMO, Pedro. Pensando a educação: inovações e experiências educacionais. Brasília: Líber Livro, 2011.

GALLO, Sílvio. Transversalidade e educação: pensando uma educação não disciplinar. In: ALVES, Nilda; GARCIA, Regina Leite (Org.). O sentido da escola. 5. ed. Petrópolis: DP, 2008. p. 15-35.

GADOTTI, Moacyr. Educação Integral no Brasil: inovações em processo. São Paulo: Editora e Livraria Instituto Paulo Freire, 2009.

GIROUX, Henry. A escola crítica e a política cultural. 3. ed. São Paulo: Cortez Autores Associados, 1992.

GOMES, Christianne Luce; PINTO, Leila Mirtes. Lazer no Brasil: o lazer no Brasil: analisando práticas culturais cotidianas, acadêmicas e políticas. In: GOMES, Christianne et al. (Org.). Lazer na América Latina: tiempo libre, ócio y recreación en Latinoamérica. Belo Horizonte: Editora UFMG, 2009. p. 67-122.

GOMES, Christianne Luce. Lazer: concepções. In: GOMES, Christianne Luce (Org.). Dicionário crítico do lazer. Belo Horizonte: Autêntica, 2004. p. 119-126.

MARCELLINO, Nelson Carvalho. A relação teoria e prática na formação profissonal em lazer. In: ISAYAMA, H. F. (Org.). Lazer em estudo: currículo e formação profissional. Esporte. Campinas: Papirus, 2010. p. 9-25.

MARCELLINO, Nelson Carvalho. Lazer e sociedade: algumas aproximações. In: MARCELLINO, Nelson Carvalho (Org.). Lazer e sociedade: múltiplas relações. Campinas: Editora Alínea, 2008. p.11-26.

MARCELliNO, Nelson Carvalho. Pedagogia da animação. Campinas: Papirus, 1990.

MARCELLINO, Nelson Carvalho. Lazer e educação. Campinas: Papirus, 1987.

MELO, Victor Andrade. A animação cultural: conceitos e propostas. Campinas: Papirus, 2006.

MELO, Victor Andrade; ALVES JÚNIOR, Edmundo D. Introdução ao lazer. Barueri: Manole, 2003.

MINAYO, M. C. S. O desafio do conhecimento: pesquisa qualitativa em Saúde. 12. ed. São Paulo: Hucitec, 2010.

PARAÍSO, Marlucy Alves. Currículo e formação profissional em lazer. In: ISAYAMA, Hélder Ferreira (Org.). Lazer em estudo: currículo e formação profissional. Campinas: Papirus, 2010. p. 27-58.

RIBEIRO, Sheylazarth Presciliana. O lazer na política pública de esporte: uma análise do programa Segundo Tempo. 2012. 148 f. Dissertação (Mestrado em Lazer) - Escola de Educação Física, Fisioterapia e Terapia Ocupacional, Universidade Federal de Minas Gerais, Belo Horizonte, 2012.

RIBETTO, Anelice; MAURÍCIO, Lúcia Velloso. Duas décadas de educação em tempo integral: dissertações, teses, artigos e capítulos de livros. Em Aberto, Brasília, v. 22, n. 80, p. 137-160, abr. 2009.

SILVA, M. S. Interfaces entre lazer e educação: o caso do Programa Escola Integrada do município de Belo Horizonte. 2013. 126 f. Dissertação (Mestrado em Lazer) - Escola de Educação Física, Fisioterapia e Terapia Ocupacional, Universidade Federal de Minas Gerais, Belo Horizonte, 2012. 
SZYMANSKI, H. (Org.). A entrevista na pesquisa em educação: a prática reflexiva. 3. ed. Brasília: Líber Livros, 2010. 4 v. (Pesquisa).

VAGO, Tarcísio Mauro. Pensar a educação física na escola: para uma formação cultural na infância e juventude. Cadernos de Formação RBCE, Florianópolis, v. 1, n. 1, p. 25-42, set. 2009.

VAGO, Tarcísio Mauro. Da rua para a escola: a escolarização de práticas corporais lúdicas da cultura urbana de Belo Horizonte (1897-1930). Motrivivência, UFSC, Florianópolis, ano VIII, n. 9, p. 269-278, dez. 1996.

\section{NOTAS}

${ }^{1}$ Os grupos pertencem às seguintes instituições: um na Universidade Federal Fluminense (RJ), um na Universidade Federal de Goiás (GO), um na Universidade Federal de Passo Fundo (RS) e dois na Universidade Estadual do Rio de Janeiro (RJ), sendo o primeiro na área de conhecimento de economia e os demais na educação. Disponível em: <http://dgp.cnpq. br/buscaoperacional/>. Acesso em: 15 jul. 2013.

2 Os trabalhos foram desenvolvidos nas seguintes unidades da UFMG: o TCC na Escola de Belas Artes, a monografia na Faculdade de Educação e a tese na Faculdade de Medicina. Disponíveis em: <http://catalogobiblioteca.ufmg.br/pergamum/biblioteca/index. php? resolution2 $=1024 \_1 \&$ tipo_pesquisa $=\&$ filtro_bibliotecas $=\&$ filtro_obras $=>$. Acesso em: 21 jul. 2013.

${ }^{3}$ A pesquisa intitulada Interfaces entre laz̧er e educação: o caso do Programa Escola Integrada do município de Belo Horizonte foi desenvolvida para obtenção do título de mestre no Programa de Pós-Graduação em Estudos do Lazer da Escola de Educação Física Fisioterapia e Terapia Ocupacional da UFMG (SILVA, 2013).

${ }^{4}$ Segundo Ribeiro (2012), a operacionalização do PST é formalizada por convênios, que são parcerias entre o Ministério da Educação, estados e municípios e outras instituições. O programa apresenta uma ramificação PST Mais Educação, que firma convênios com escolas inscritas no Programa Mais Educação do Ministério da Educação. O Ministério do Esporte e o Ministério da Educação firmaram parceria para promover a inserção do PST nas escolas do Programa Mais Educação, assim no Programa Escola Integrada. A ideia é estabelecer convênios com o município de Belo Horizonte para o desenvolvimento do esporte educacional, respeitando as diretrizes do PST.

Submetido: 30/10/2015

Aprovado: 14/03/2016

Contato:

Marcília de Souza Silva

Oricolé/EEFFTO/UFMG

Av. Antonio Carlos, 6627, Pampulha

Belo Horizonte |MG | Brasil

CEP 31.270-901 